\title{
Resolução de Problemas: Uma Análise Realizada com Estudantes do Ensino Médio de uma Escola Urbana e de uma Escola do Campo
}

\section{Problem Solving: An Analysis Carried out with High School Students from an Urban and a Rural School}

\section{Glessyan de Quadros Marques Brasil Marcia Borin da Cunha Brasil}

Este estudo foi fundamentado na teoria da Resolução de Problemas e teve como objetivo investigar as atitudes/ações empregadas por estudantes do ensino médio quando resolvem problemas abertos, apresentando uma análise das soluções fornecidas por eles. A pesquisa, de abordagem qualitativa, contou com a participação de 25 estudantes do ensino médio de duas escolas públicas localizadas em um município do estado do Paraná, sendo uma escola urbana e uma escola do campo. Foram fornecidos aos estudantes três problemas abertos, hipotéticos, que apresentavam situações do cotidiano relativas a um vazamento de gás de cozinha, ao descarte de embalagens em um rio e à prevalência de cáries dentárias numa população. A partir desses problemas, os estudantes tinham de descrever formas de resolução e justificá-las. Para analisar as respostas fornecidas pelos estudantes foi utilizado a Análise de Conteúdo, proposta pela pesquisadora francesa Laurence Bardin. Os resultados apontam para o fato de que a maioria dos estudantes pesquisados tomam decisões que não solucionariam os problemas propostos e essas decisões carecem de justificativas.

Palavras-chave: Resolução de Problemas; Escrita; Ensino de Ciências.

This study was based on Problem Solving theory and aimed to investigate the attitudes/ actions applied by high school students when solving open problems, in order to present an analysis of the solutions that they provided. Twenty-five high school students from two public schools located in a municipality in the state of Paraná, being an urban school and a rural one, participated in this qualitative research study. The students were provided with three open and hypothetical problems that presented everyday situations related to a kitchen gas leak, the dumping of packaging in a river and the prevalence of dental caries in a population. From these problems, students had to describe ways of solving them and justify those solutions. To analyze the answers provided by the students, the method called Content Analysis, by the French researcher Laurence Bardin, was used. The results point to the fact that most of the students surveyed make decisions that 
would not solve the problems proposed, and that these decisions lack justification.

Keywords: Problem Solving; Writing; Science teaching.

\section{A Resolução de Problemas no Ensino de Ciências}

Resolver problemas constitui-se como uma atividade humana fundamental, existente desde os tempos mais remotos, quando os primeiros homens tiveram que desenvolver métodos para solucionar os seus quefazeres cotidianos de sobrevivência. E, na tentativa de solucioná-los, eles “[...] criaram maneiras de comparar, classificar e ordenar, medir, quantificar, inferir os elementos fundamentais [...]” (Huanca, 2006, p. 20).

Mesmo assim faz pouco tempo que foram iniciadas as investigações em Resolução de Problemas - RP como abordagem didático-pedagógica nas mais diversas áreas da Educação. Foi somente a partir do século XX, mais especificamente entre os anos 1980 e 1990, que as pesquisas sobre esse tema ganharam força, inicialmente na área da Matemática e, posteriormente, estendendo-se para áreas do ensino de Ciências, constituindo-se assim uma produtiva linha de investigação (Oñorbe, 2003; Sigarreta, Rodríguez, \& Ruesga, 2006).

As investigações sobre RP nas disciplinas de Física e de Química, de acordo com Oñorbe (2003), foram iniciadas antes das pesquisas nas áreas de Biologia e de Geologia, isso porque, no início, se entendia a RP como um campo específico voltado às disciplinas embasadas em cálculos. Paulatinamente, começou-se a inserir no ensino em geral um contexto de resolução de problemas mais amplo e não apenas numérico.

Atualmente, diversos pesquisadores e educadores têm estudado e defendido as potencialidades desse método didático-pedagógico com vistas a oferecer uma formação mais abrangente, que possibilite o desenvolvimento de habilidades diversas, de atitudes e de aprendizagem de novos conhecimentos científicos, que geralmente não são alcançados com o ensino tradicional, que presume somente perguntas e respostas prontas (Leite, \& Esteves, 2005; Lopes, 1994; Ocampo, 2015; Oñorbe, 2003; Palacios, 1998).

A RP permite a proposição de problemas aos estudantes com vistas ao desenvolvimento de habilidades diversas, tanto de natureza básica, como de natureza complexa, envolvendo, por exemplo, a memória, o raciocínio lógico, a linguagem, o resolver problemas, a tomada de decisão, entre outras. No ensino de Ciências, essa abordagem possibilita problematizar fatos científicos a partir da realidade dos estudantes, oferecendo um ensino que contribua para a formação do cidadão crítico e autônomo e também para a compreensão e a explicação dos fenômenos da natureza.

Segundo Ocampo (2015), a RP pode ser entendida sob diferentes óticas. Noâmbito da Matemática há uma preocupação maior em propor modelos para facilitar o processo de resolução de problemas em sala de aula, fornecendo subsídios (treinamento) para os professores auxiliarem os alunos se tornarem melhores "solucionadores de problemas". Por outro lado, no ensino de Ciências a preocupação está mais voltada ao caminho percorrido pelo estudante para chegar a uma possível solução do problema. 
A RP, enquanto uma vertente originária da psicologia cognitiva, foi descrita por Lopes (1994) como um processo dinâmico e contínuo de construção de conhecimento, processo que pode ocorrer tanto na comunidade científica, como na atividade psicológica de aprendizagem dos alunos ou, ainda, na atividade cotidiana dos cidadãos.

Quando esse processo é proposto nas salas de aula, ele pode partir tanto de uma situação problemática ampla quanto de um problema específico fornecido pelo professor. $\mathrm{O}$ professor atua como orientador do processo e estabelece um papel ativo ao aluno no decorrer de todo o processo de busca de informações para a solução do problema (Lopes, 1994).

No ensino de Ciências, de acordo com Freire, Silva Júnior e Silva (2011), entendese que o significado de problema está relacionado a uma dificuldade segundo a qual não se sabe a resposta ou não se possuem meios diretos para a sua solução. $O$ problema consiste então em um obstáculo a ser enfrentado pelo indivíduo ou pelo grupo. Além disso, o problema pode ser entendido como "[...] algo para o qual não se conhece a resposta e nem se esta existe. A resolução do problema refere-se ao processo mediante o qual tal situação incerta é esclarecida, implicando em maior ou menor medida, a mobilização e 'aplicação' de conhecimentos e procedimentos por parte daquele que a soluciona" (Freire et al., 2011, p. 110).

Um problema pode apresentar inúmeras características, o que o diferencia de um exercício. Em síntese, Lopes (1994, p. 27) aponta que o problema inibe "[...] a tendência ao imediatismo, convidando à reflexão e compreensão da situação física antes de se começar a manipular a informação numérica [...]", havendo uma avaliação dos possíveis caminhos de resolução, o que não acontece quando se resolve um exercício, para o qual, para solucioná-lo, há somente um caminho e uma solução possível.

Com relação às características dos problemas em RP, eles podem ser definidos quanto ao seu tipo (problemas lápis e papel, situação problemática, questões, enunciados, etc.) e/ou de acordo com os procedimentos empregados para a sua resolução (investigação, experimentação, pesquisa, etc.) (Lopes, 1994).

Palacios (1998) explica que os problemas podem ser de determinado campo do conhecimento (Física, Química, Biologia, entre outros), fechados ou abertos (quanto à liberdade de resolução), qualitativos ou quantitativos (quanto ao tipo de abordagem) e experimentais ou criativos (quando à forma de resolução). Para a sua resolução, os problemas podem empregar procedimentos como exercícios (de aplicação direta), algoritmos (com sequência de operações), heurísticos (com estratégias de planejamento) ou criativos (com estratégias diversas).

Os problemas ainda podem ser classificados quanto ao tipo de conhecimento utilizado em sua resolução. Autores como Pozo e Crespo (1998) os classificam em três tipos. São eles: problemas cotidianos, problemas científicos e problemas escolares.

Problemas cotidianos, para os autores, estão relacionados a todo tipo de situação do dia a dia que requer uma solução prática, em que o sucesso da ação é mais valorizado do que os meios utilizados para a sua elucidação. Nesse tipo de problema, “[...] a reflexão 
é direcionada para a eficácia da ação e não há espaços para conceituações" (Fontana, 2015, p. 6).

Os problemas científicos, segundo Francisco Jr., Ferreira e Hartwig (2008), geralmente nascem "[...] de um evento [em] que as teorias não conseguem explicar, necessitando de uma reorientação teórica" (Francisco Jr. et al., 2008, p. 83). São problemas que possuem metodologia inerente à sua resolução, sendo reduzidos a fases de observação, de formulação de hipóteses, de planejamento e de execução das experiências e confronto das hipóteses a partir dos dados obtidos (Fontana, 2015).

Os problemas escolares são aqueles oferecidos aos estudantes com o objetivo de proporcionar a aprendizagem de conteúdos conceituais, o desenvolvimento de procedimentos e atitudes próprios da ciência, e que possam proporcionar uma melhor compreensão de questões relacionadas ao funcionamento cotidiano da natureza e da tecnologia. (Nieto, 2002; Pozo, \& Crespo, 1998).

Nessa pesquisa, os problemas propostos aos estudantes mesclam algumas das características descritas acima e foram denominados como um "[...] enunciado que aparece a partir de um contexto problemático e que delimita o conhecido do desconhecido" (Lopes, 1994, p. 37), ou seja, que apresenta aspectos conhecidos e desconhecidos ao solucionador, necessitando de investimento em conhecimentos diversificados para a respectiva resolução. Esses problemas podem ser comparados ao que Sá (2010) denomina de problemas autênticos, pois

[...] apresentam uma situação (real ou simulada) contextualizada na vida cotidiana, com a complexidade adequada aos propósitos de ensino, e que requerem o uso do pensamento lógico e crítico e a consideração de explicações alternativas. Tais problemas podem assumir um caráter científico ou sócio-científico e encontram aplicação em diversas disciplinas (Duschl; Osborne, 2002 citado por Sá, 2010, p. 14).

Considerando a teoria da RP, elaboramos problemas abertos, ou seja, problemas que não apresentam apenas uma solução possível, mas diversas possibilidades de resolução (Jessup, Oviedo, \& Castellanos, 2000) e que podem ser analisados a partir de critérios específicos.

Fornecemos aos estudantes problemas hipotéticos, do tipo lápis e papel, os quais exigiam uma resolução escrita, de natureza teórica. Com isso, esperávamos que os estudantes - solucionadores de problemas - mobilizassem conhecimentos variados, como o conhecimento científico ou o senso comum e, além disso, a reflexão e a tomada de decisão, para resolver os problemas propostos.

Neste trabalho, a tomada de decisão é compreendida como uma capacidade de ação para selecionar ou julgar situações gerais ou específicas de maneira racional, quando se têm meios alternativos de atuação sobre o problema (Santos, \& Mortimer, 2001). Diante disso, analisamos se as decisões tomadas pelos estudantes solucionam ou não o problema proposto.

Com relação à relevância da Resolução de Problemas no ensino de Ciências, Lopes (1994) define a RP como um processo e não como uma atividade/tarefa pontual. 
Assim, segundo ele:

A vivência de um processo de resolução de problemas não só aumenta os saberes, como também desenvolve algumas competências cognitivas, tais como as capacidades de formular, identificar, converter e resolver problemas. Gera igualmente outros processos também importantes na formação científica dos alunos, como, por exemplo, a formulação de hipóteses, o controle de variáveis e desenvolve, para além disso, várias atitudes desejáveis, tais como a persistência. (Lopes, 1994, p. 7).

Como descrito no trecho acima, acredita-se que a RP pode permitir o desenvolvimento de diversas competências científicas, sociais, etc., o que a torna um tema que deveria estar presente no currículo das disciplinas científicas escolares. Acredita-se que o currículo deva ser planejado para favorecer situações suficientemente abertas, que induzam os alunos a uma busca e apropriação de estratégias que forneçam respostas, tanto a perguntas escolares como aos questionamentos cotidianos (Echeverría, \& Pozo 1998).

Por outro lado, Leite e Esteves (2005) salientam que a RP pode desempenhar diferentes funções no contexto nos processos de ensino aprendizagem em sala de aula. Ela pode atuar como ponto de partida para aprendizagens, no aprofundamento ou ainda na avaliação da aprendizagem. Isso significa que a RP pode ser empregada pelos professores em momentos distintos ou complementares nas salas de aula, o que contribui com a ideia de construção do conhecimento e o desenvolvimento de habilidades dos alunos, habilidades essas que certamente só serão alcançadas em longo prazo e com certo esforço.

Pensando nisso é que o professor pode oferecer condições para que os estudantes exercitem suas habilidades em sala de aula. É ele quem elabora, define e propõe os problemas, mediando a relação do aluno com o conhecimento para alcançar os seus objetivos de ensino.

Entretanto, é conveniente destacar a importância de haver investimentos em formação de professores, de modo a possibilitar que eles conheçam essa abordagem e consigam desenvolvê-la de acordo com uma didática adequada, como, por exemplo, no modelo de RP como investigação descrito por Gil Pérez et al. (1992), o qual se aproxima da abordagem empregada por cientistas.

Por outro lado, Freire et al. (2011) apontam que existem dificuldades quanto ao uso da RP na escola, já que essa abordagem exige uma maior dedicação, seja no planejamento, seja na execução e na avaliação das atividades por parte do professor. A tarefa do professor "[...] não se reduz a selecionar problemas que possam ser mais ou menos compatíveis com determinados conteúdos teóricos", mas também despertar o interesse nos estudantes e conseguir que o estudante converta em seus, os problemas que o professor elege como ponto de partida do processo de aprendizagem. (Freire et al., 2011, p. 107),

Assim, no caso da adoção da RP, além de as exigências serem maiores por parte do professor, há também a necessidade de os alunos mudarem as suas atitudes, pois a aprendizagem por meio de problemas requer dedicação do aluno, que precisa ultrapassar 
a perspectiva da passividade, normalmente assumida em ambientes tradicionais de ensino (Freire et al., 2011).

Ao fazer uma busca na literatura sobre o tema, observamos que a abordagem de RP é estudada em inúmeras pesquisas e analisada sob diversas perspectivas no ensino de Ciências. Entretanto, como pode ser observado nos trabalhos de revisão bibliográfica de Costa e Moreira (2006) e de Freire et al. (2011), as pesquisas que visam conhecer a forma como os estudantes solucionam problemas, em especial problemas do cotidiano, são raras. Por isso, a necessidade de realizá-las para levantar novos questionamentos e reflexões sobre o tema.

A partir dessas ideias, idealizamos essa pesquisa oferecendo a dois grupos de estudantes (um deles de uma Escola do Campo e o outro de uma Escola Urbana), problemas abertos contendo situações do cotidiano, situações que podem acontecer com qualquer pessoa em algum momento da vida, ou seja, eventos que podem ou não ter sido vivenciados pelos estudantes e, para as quais, se exige conhecimento científico, atitude e tomada de decisão para a sua resolução.

A escolha desses dois grupos ocorreu devido à nossa intenção de comparar qualitativamente as respostas de estudantes pertencentes a contextos escolares diversos, o campo e a cidade, levando em conta que a Escola Urbana e a Escola do Campo poderiam ter especificidades diferentes, referentes, por exemplo, a abordagens de ensino relativas à Educação Geral e Educação do Campo, respectivamente. Esse fato poderia sugerir resultados diversificados quanto à resolução dos problemas propostos. Contudo, foi constatado em outras etapas da pesquisa, envolvendo a análise de documentos legais, que a escola identificada neste artigo como Escola do Campo, é reconhecida como uma Escola do Campo, mas não é orientada por diretrizes educacionais específicas da Educação do Campo. Assim, ressaltamos que ambas as escolas pesquisadas são orientadas por modelos curriculares semelhantes.

Enfatizamos que nossos objetivos foram avaliar as decisões tomadas pelos estudantes para solucionar os problemas propostos e analisar o conteúdo das respectivas respostas, observando se há o emprego de estratégias (atitudes/ações) que solucionariam o problema em questão, de modo a verificar se as respostas fornecidas são embasadas no conhecimento científico ou no conhecimento de senso comum.

\section{Metodologia da Pesquisa}

Esta pesquisa, de abordagem qualitativa e de caráter descritivo, investigou estudantes de duas escolas de um município localizado no interior do Paraná, Brasil, uma delas identificada como Escola Urbana e a outra como Escola do Campo. Elas foram selecionadas a partir de alguns critérios, como: i) as escolas estarem localizadas em contextos diferentes (cidade e campo), de modo que pudéssemos fazer um comparativo entre os resultados apresentados pelos estudantes das duas escolas; ii) as escolas pertencerem à rede pública de ensino; iii) os estudantes frequentarem o $2^{\circ}$ ano do ensino médio, etapa intermediária do ensino médio; iv) existir apenas uma turma do 
$2^{\circ}$ ano do ensino médio no período matutino nas escolas; e v) os estudantes das escolas residirem no entorno das mesmas.

Os dados foram coletados no segundo trimestre do ano de 2015. Esses dados fizeram parte de uma pesquisa de mestrado, submetida e aprovada em Comitê de Ética em Pesquisa. Por questão de espaço, optamos por apresentar, neste artigo, somente parte dos resultados, que foram desvinculados da pesquisa inicial sem causar prejuízos à sua análise.

Participaram da pesquisa 25 estudantes do $2^{\circ}$ ano do ensino médio, regular, do período matutino. Deles, 9 estudantes eram da Escola do Campo e 16 eram da Escola Urbana. Ambas as escolas são consideradas de pequeno porte, por isso recebem uma demanda relativamente baixa de estudantes, que resulta em turmas com um número reduzido de estudantes nas salas.

Os dados foram coletados por meio de três problemas abertos, entregues aos estudantes em folha impressa, na qual eles deveriam escrever suas respostas. Os problemas fornecidos foram elaborados pelos próprios pesquisadores e apresentavam temas do cotidiano, pois se referem a problemáticas relacionadas a situações que podem acontecer tanto no contexto da cidade como no contexto do campo. No primeiro problema (problema 1) analisamos as providências/atitudes tomadas pelos estudantes em caso de um vazamento de gás de cozinha; no problema 2 analisamos as explicações fornecidas pelos estudantes para o caso de alguém poluir um rio com embalagens de agrotóxicos; e, no problema 3, analisamos a tomada de decisão no caso de haver incidência de cáries dentárias em uma população.

Para a análise dos problemas, fizemos o uso do método "Análise de Conteúdo", de Bardin (2009), que nos fornece um conjunto de técnicas que permitem analisar as comunicações. O método consiste em três etapas fundamentais, que são: a pré-análise, a exploração do material e o tratamento dos resultados (Bardin, 2009). Nessas etapas estão incluídas a organização da análise, a codificação, a inferência, a análise categorial e a interpretação. Nesta pesquisa, as categorias foram elaboradas a posteriori, emergindo das respostas dos estudantes.

Por meio do método da "Análise de Conteúdo", as respostas fornecidas pelos estudantes aos problemas, foram digitadas integralmente e organizadas em quadros de acordo com um código, no qual utilizamos a letra $E$ seguida da letra U ou C para identificar a Escola Urbana ou a Escola do Campo, e um número correspondente para cada estudante. As respostas foram organizadas em categorias (C), que facilitaram a análise dos dados. Devido à variedade de respostas obtidas, foi necessário estabelecer critérios de análise para cada questão, os quais serão discutidos junto à apresentação dos resultados.

Como critério de confiabilidade na pesquisa, as análises foram anteriormente disponibilizadas entre os pares, que avaliaram os resultados da pesquisa em uma banca de defesa composta por três membros. 


\section{O Contexto da Pesquisa}

O início da pesquisa se deu por meio de uma visita técnica, a fim de conhecer os principais espaços das escolas. Quanto ao espaço escolar, é conveniente destacar que essas escolas estão localizadas em ambientes relativamente diferentes. Uma delas está situada em um contexto reconhecidamente urbano, recebendo estudantes moradores do respectivo bairro e a outra se situa em um contexto do campo, onde prevalecem características próprias desse espaço, recebendo estudantes moradores do próprio distrito e da zona rural. Em termos de edificação, as duas escolas são diferentes, pois a Escola do Campo conta com uma estrutura física satisfatória, que, apesar de antiga, está organizada em um amplo espaço físico com área verde e vários espaços de lazer. Por outro lado, a Escola Urbana dispõe de uma boa estrutura física em termos de construção, mas está organizada em um pequeno espaço físico, com apenas um local aberto de lazer e recreação.

Em uma etapa inicial realizamos uma conversa informal com a professora das turmas pesquisadas, já que ela atuava em ambas as escolas e turmas pesquisadas, e a mesma havia disponibilizado suas aulas para a realização da pesquisa. A professora nos indicou que os estudantes já haviam tido algum contato com problemas de natureza aberta, mais especificamente com problemas contextualizados, os quais eram apresentados no livro didático de Química utilizado por ela para trabalhar conteúdos. Contudo, a professora reforçou que não costumava desenvolver atividades didáticas para além da problematização disponível no livro didático.

A pesquisa aconteceu nos contextos de sala de aula. Inicialmente, fomos apresentados aos estudantes das turmas selecionadas pela professora da disciplina. Naquela ocasião, explicamos nossa intenção em realizar a pesquisa com os estudantes e explanamos as condições éticas da pesquisa e como ela aconteceria. Este foi um momento destinado ao entrosamento do pesquisador com os estudantes, e eles puderam tirar suas dúvidas sobre a pesquisa. Todos os estudantes foram informados que sua participação era de livre escolha. Logo de início percebemos que os estudantes da Escola Urbana apresentaram um maior interesse em participar e até certa empolgação. Por outro lado, os estudantes da Escola do Campo se mostraram mais retraídos, mas não se negaram a participar.

Em um segundo momento, uma das pesquisadoras realizou a coleta de dados em ambas as escolas, fornecendo aos estudantes os problemas abertos. A pesquisadora realizou a leitura dos problemas e procurou estabelecer um ambiente agradável, no qual os estudantes respondessem os problemas livremente, sem a preocupação de obter uma nota que os qualificasse, já que eles não seriam avaliados quantitativamente. Deste modo, eles responderam os problemas com seus próprios conhecimentos, sem a interferência da pesquisadora ou da professora da disciplina, e sem haver nenhum tipo de consulta a materiais de apoio. A seguir apresentamos a análise e a discussão dos resultados. 


\section{Análise do problema 1: Vazamento de gás de cozinha}

Problema: Certo dia você chega em sua casa e percebe que há um vazamento de gás de cozinha (de pequena proporção), pois existe um cheiro característico. Apresente duas providências que devem ser tomadas para resolver o problema, antes mesmo de chamar ajuda, explicando o motivo pelo qual você tomaria essas providências. (Problema adaptado do trabalho de Marques e Cunha, 2015).

Eventuais vazamentos de gás de cozinha em residências são um problema relativamente comum e, na maioria das vezes, estão relacionados ao mau uso dos botijões pelos seus usuários, ao descuido com relação à instalação, à manutenção e armazenagem do botijão e de seus equipamentos (Sindigás, 2008). Mas outros fatores também podem agravar o problema como o esquecimento decorrente de chamas acesas no fogão, ignorar pequenos vazamentos, desconhecer medidas de segurança e etc. Entretanto, grande parte dos vazamentos de gás poderia ser evitada se a população em geral conhecesse as causas e os efeitos de um vazamento de gás e tomasse as medidas de segurança adequadas para impedir acidentes graves.

A partir do problema proposto, procuramos analisar que atitudes/providências foram tomadas por estudantes do ensino médio para resolvê-lo. Avaliamos essas providências levando em conta os perigos ocasionados pelo vazamento de gás de cozinha $(\mathrm{GLP})^{1}$ que são relativos à sua inflamabilidade e ao seu efeito anestésico e asfixiante (Sindigás, 2008). Para estabelecer critérios de análise também consideramos as "dicas de segurança” fornecidas pelo Corpo de Bombeiros (2011).

Caso aconteça um vazamento de gás, é importante saber que, quando o GLP entra em contato com uma fonte ígnea, ele inflama e pode provocar uma explosão, principalmente se isso acontecer em um ambiente não ventilado. Além disso, se o gás for inalado em grandes concentrações, ele provoca um efeito anestésico e asfixiante, devido à redução da concentração de oxigênio no ar (Sindigás, 2008).

Como, contudo, no enunciado do problema foi proposto que o vazamento era de pequena proporção, então avaliamos como duas providências fundamentais e suficientes para solucionar o problema pelos estudantes, a ação de fechar o registro e/ ou válvulas do gás e abrir portas e janelas, concomitantemente, pois essas providências impediriam que o gás continuasse vazando e extinguiriam os perigos provenientes do seu vazamento. Além dessas, outras providências também poderiam ser tomadas, como: identificar o local do vazamento, fechar os acendedores do fogão, não gerar faíscas de nenhuma natureza, retirar o botijão do ambiente, pedir ajuda a um órgão especializado, etc. Assim, esperávamos que, nessa questão, os estudantes apresentassem as providências fundamentais e justificassem adequadamente as suas ações.

Na Figura 1 encontram-se as respostas dos estudantes da Escola Urbana para o Problema 1, as categorias correspondentes e a respectiva análise dos dados.

1 GLP: Gás Liquefeito de Petróleo. 


\begin{tabular}{|c|c|}
\hline $\mathrm{Cl}$ & Solução do problema com providências fundamentais \\
\hline EU3: & $\begin{array}{l}\text { "Desligando o gás e abriria todas as portas e janelas para ventilar. Assim o gás iria acabar de vazar e } \\
\text { iria se espalhar sem riscos" }\end{array}$ \\
\hline EU5: & "eu desligaria o botijão abriria a casa para sair o fedor" \\
\hline EU11: & "fechar o gás, abrir a casa e ligar para alguém resolver este problema" \\
\hline EU13: & "fechar o gás e abrir as janelas e porta, para o gás sair e não acender nada já que pode pegar fogo" \\
\hline EU15: & $\begin{array}{l}\text { "desligar o gás para parar o vazamento e abrir as portas e janelas para que o gás não se acumule e } \\
\text { saia" }\end{array}$ \\
\hline $\mathrm{C} 2$ & Solução do problema com providência perigosa \\
\hline EU9: & $\begin{array}{l}\text { “fechar a válvula do botijão e, se possível, leva-lo para o exterior da casa e abrir janelas para arejar o } \\
\text { ambiente, evitando, assim, o vazamento de mais gás e 'retirando' ele do ambiente interno da casa, visto } \\
\text { que ele, além de ser inflamável, pode deixar o indivíduo inconsciente" }\end{array}$ \\
\hline C3 & Solução parcial do problema \\
\hline EU2: & $\begin{array}{l}\text { "Abriria o local sem acender a luz ou luzes qualquer coisa que possa gerar faísca, e retiraria o objeto } \\
\text { que está espalhando o gás". }\end{array}$ \\
\hline EU8: & "desligar o gás e não usar materiais com explosão (micro-ondas, etc.)" \\
\hline EU14: & $\begin{array}{l}\text { "primeiro fechar o registro do gás para evitar que vaze mais gás e provoque algum acidente e logo após } \\
\text { pegaria uma buchinha de cozinha com sabão e passaria sobre o registro para observar se há ainda } \\
\text { vazamento." }\end{array}$ \\
\hline EU7: & "eu vejo se os botões do fogão estão ligados e vazando ai eu desligo" \\
\hline EU16: & "primeiramente deixaria a casa bem ventilada abrindo as janelas e levaria o botijão pa \\
\hline $\mathrm{C4}$ & Providências perigosas ou que não solucionariam o problema \\
\hline EU1: & $\begin{array}{l}\text { "eu tomaria noção da intensidade do cheiro, sabendo assim, se a melhor forma seria rapidamente } \\
\text { resolver o problema do vazamento retirando o botijão ou algo assim, ou se o vazamento fosse mais } \\
\text { intenso, e de maior risco de alguma tragédia chamaria ajuda de bombeiros ou equipes de saúde" }\end{array}$ \\
\hline EU4: & "verificar se a boca do fogão está aberta e ver se a mangueira do gás está frouxa" \\
\hline EU6: & "desconectar a válvula e recoloca-la para ver se o problema foi apenas na válvula" \\
\hline EU10: & $\begin{array}{l}\text { "jamais ligaria a luz pois poderia acontecer uma explosão e se realmente achar que é gás iria ver onde } \\
\text { está vazando e se dá para apagar" }\end{array}$ \\
\hline EU12: & $\begin{array}{l}\text { "primeiro iria ver o que é. E depois tentar arrumar pois se for coisa que consigo fazer não necessita } \\
\text { chamar técnico" }\end{array}$ \\
\hline
\end{tabular}

Figura 1. Respostas dos estudantes da Escola Urbana ao Problema 1

Fonte: As autoras

Na Figura 1 , as respostas dos estudantes foram organizadas em quatro categoriais C1, C2, C3 e C4. De forma geral, observamos que, dos 16 estudantes entrevistados, apenas 6 apresentariam as providências fundamentais para resolver o problema em questão.

$\mathrm{Na}$ categoria C1, "Solução do problema com providências fundamentais", encontram-se as respostas de cinco estudantes (EU3, EU5, EU11, EU13 e EU15), que tomariam as providências necessárias resolver o problema, que são relativas à ação de desligar/fechar a válvula/registro do gás e de abrir portas e janelas da casa.

Destacamos a resposta de EU11, na qual, além de afirmar que tomaria as providências fundamentais, chamaria ajuda de outra pessoa, o que é válido, principalmente quando não há certeza quanto a que medidas devem ser tomadas numa 
situação como essa.

O estudante EU13 também tomaria as providências fundamentais e, além delas, ele não acenderia nada que pudesse provocar fogo. Percebe-se que há, nessa justificativa, a noção de inflamabilidade do gás. Entretanto falta uma explicação mais detalhada, embasada no conhecimento científico que demonstre um entendimento sobre o fenômeno.

Na categoria C2, "Solução do problema com providência perigosa", temos a resposta do estudante EU9, o qual apresentou as providências fundamentais para resolver o problema e as justificou adequadamente. Ele menciona que o gás de cozinha é inflamável e que ele pode deixar o indivíduo inconsciente, o que está correto do ponto de vista do conhecimento científico e dos órgãos de distribuição do gás. Diferentemente, contudo, o que desabona sua resposta é o fato de ele ter dito que tentaria levar o botijão para o exterior da casa. Consideramos essa atitude perigosa e desnecessária de ser tomada por um adolescente, pois oferece perigo referente a ação de desinstalar o botijão de gás e fazer a sua remoção, bem como desnecessária, pois as medidas fundamentais já solucionariam o problema.

Foram organizadas na categoria C3, "Solução parcial do problema", as respostas de cinco estudantes (EU2, EU7, EU8, EU14 e EU16) que apresentaram apenas uma das providências necessárias para solucionar o problema.

Destacamos a resposta do estudante EU14, que apontou que fecharia o registro do gás como uma providência adequada e que extinguiria o vazamento. Como uma segunda providência, ele testaria se o vazamento continuava ou não, com o auxílio de uma esponja de cozinha e detergente. Essa é uma ação válida e muito utilizada por funcionários das revendedoras de gás que instalam os botijões em residências, para verificar a presença de possíveis vazamentos. Essa solução, contudo, não descarta o perigo de asfixia, em caso de manter o ambiente fechado, exigindo-se, portanto, que também portas e janelas sejam abertas para resolver o problema.

EU16 apresentou apenas uma das providências necessárias, aquela que refere à ventilação da casa e, além dessa, ele menciona que levaria o botijão para fora de casa, ação que como afirmado anteriormente, consideramos como perigosa para um adolescente.

Na categoria C4, "Providências perigosas ou que não solucionariam o problema", organizamos as respostas de seis estudantes - EU1, EU4, EU6, EU10, EU12 e EU16 -, os quais não conseguiriam solucionar o problema por conta de terem proposto atitudes com algum grau de periculosidade, ou que não extinguem o vazamento do gás.

A resposta de EU1 não apresentou nenhuma das providências fundamentais, ao invés disso o estudante optou por uma tentativa perigosa de retirada do botijão do local, o que, segundo ele, seria a mais rápida, porém ele desconsiderou os riscos dessa retirada.

Nas respostas dos estudantes EU4, EU10 e EU12 observa-se uma preocupação de encontrar o vazamento, ver onde ele está, ação que se mostra válida. Contudo, identificar onde está o problema e se ele existe, não implica resolvê-lo. Então, apesar de algumas dessas propostas para encontrar o problema serem necessárias, elas não o solucionam 
efetivamente.

Em sua resposta, o estudante EU6 deduz que o problema estava na válvula do gás, ou seja, no registro do gás. Ele menciona que desconectaria a válvula e a conectaria novamente, porém essa ação só teria efeito caso o problema estivesse na válvula do gás, mas poderia acarretar em um vazamento ainda maior. Essa ação jamais deve ser tomada sem antes fechar o registro do gás.

De modo geral, observamos que apenas seis estudantes da Escola Urbana solucionariam o problema do vazamento de gás, pois apresentariam pelo menos duas providências fundamentais. Por outro lado, notamos que raros são os estudantes que justificam/explicam com clareza o motivo pelo qual tomariam determinada atitude/ providência. Isso se deve ao fato de que, muito provavelmente, essas explicações sejam motivo de dúvida ou desconhecidas - o que indica que alguns dos estudantes pesquisados tomam determinadas decisões sem saber ao certo o motivo da ação. Algumas ações nos parecem instintivas, automáticas, que não demonstram uma reflexão ou algum conhecimento mais aprofundado sobre os problemas relativos a um vazamento de gás de cozinha.

A seguir, apresentamos as respostas dos estudantes da Escola do Campo e as análises do Problema 1 e as categorias.

\begin{tabular}{|c|c|}
\hline $\mathrm{Cl}$ & Solução do problema com providências fundamentais \\
\hline EC2: & $\begin{array}{l}\text { "Abrir todas as janelas e portas para ventilar o ambiente e deixar o gás sair. Fechar o local do vazamento, } \\
\text { deixando de eliminar o gás" }\end{array}$ \\
\hline $\mathrm{C} 2$ & Solução parcial do problema \\
\hline EC3: & $\begin{array}{l}\text { "Desligaria a energia elétrica, para não causar nenhuma explosão. Desligaria o gás, para não ter mais } \\
\text { vazamentos de gás" }\end{array}$ \\
\hline EC1: & $\begin{array}{l}\text { "Abriria janelas e portas, para o gás sair mais facilmente e não mexeria em nenhum utensílio eletrônico, } \\
\text { nem mesmo interruptores, pois uma única faísca causaria uma explosão" }\end{array}$ \\
\hline EC6: & "Não ligar as luzes ou algum tipo de interruptor e abrir portas e janelas" \\
\hline EC7: & "Desligar o gás e a energia para não causar nenhuma explosão" \\
\hline EC9: & $\begin{array}{l}\text { "Abriria as portas e janelas para sair o cheiro e passaria espuma ao redor da válvula e verificaria se } \\
\text { realmente houve o vazamento" }\end{array}$ \\
\hline C3 & Providências perigosas ou que não solucionariam o problema \\
\hline EC4: & $\begin{array}{l}\text { "Primeiramente não pode se acender a luz pois qualquer faísca pode causar em chamas e depois é } \\
\text { necessário tirar o bojão de gás de dentro de casa" }\end{array}$ \\
\hline EC5: & $\begin{array}{l}\text { "Primeiro retirar o bujão de gás, pra que não exploda dentro da cozinha, e levar em algum lugar mais } \\
\text { retirado de perto de casa." }\end{array}$ \\
\hline EC8: & "Iria fechar o local pois o cheiro se torna insuportável" \\
\hline
\end{tabular}

Figura 2. Respostas dos estudantes da Escola do Campo ao Problema 1.

Fonte: as autoras

A análise das respostas dos estudantes da Escola do Campo ao Problema 1 permitiu categorizá-las em três categorias.

Na categoria C1, "Solução do problema com providências fundamentais", temos a resposta de EC2. Como uma providência fundamental, ele mencionou que abriria portas 
e janelas, justificando em termos de favorecer a ventilação do ambiente. Como outra providência fundamental, ele informou que fecharia o local do vazamento. Deduzimos que ele pode estar se referindo à válvula/registro do gás, e justificou adequadamente, que isso deixaria de eliminar o gás. Mesmo assim, faltou deixar claro, nessa resposta, o que (qual local), precisamente, deveria ser fechado.

$\mathrm{Na}$ categoria C2, "Solução parcial do problema”, foram inseridas as respostas de cinco estudantes EC3, EC1, EC6, EC7 e EC9. Consideramos as respostas fornecidas por esses estudantes como parcialmente corretas, pois, de forma geral, eles apresentaram apenas uma das providências fundamentais para solucionar o problema, ou seja, alguns mencionaram que fechariam a válvula do gás e outros mencionaram que abririam portas e janelas, além de outras providências, como evitar gerar faíscas não acionando interruptores elétricos ou mecanismos similares.

As respostas de EC3 e de EC7 se destacam, pois esses estudantes mencionaram que, além de desligarem o gás, eles também desligariam a energia elétrica. Essas ações são válidas, pois cessariam o vazamento e evitariam faíscas geradas por equipamentos elétricos que poderiam produzir explosão. Ocorre, entretanto, que manter um ambiente fechado não exclui o perigo de asfixia. $\mathrm{O}$ estudante EC3 ainda justifica adequadamente o motivo de suas ações.

Por outro lado, os estudantes EC1 e EC6 mencionaram que abririam portas e janelas e evitariam acender ou apagar qualquer interruptor. Com essas ações, eles não solucionariam efetivamente o problema, pois o gás continuaria vazando e o perigo permaneceria, mas se percebe que há, nessas respostas, algum conhecimento sobre inflamabilidade. EC1 justifica os motivos de suas ações.

Apesar de os estudantes EC1, EC3 e EC7 terem mencionado a questão do perigo de uma explosão, o que indica que eles têm uma ideia de que o gás é inflamável, nenhum deles deixou esse conhecimento explícito em suas respostas.

Nessa categoria C2 temos a resposta de EC9, o qual mencionou que, além de abrir portas e janelas, também passaria espuma ao redor da válvula de gás para verificar se realmente houve vedação do vazamento. A segunda providência fornecida pelo estudante é válida, mas não solucionaria o vazamento, pois, como já dito anteriormente, verificar se há vazamento, por meio desse teste, não é suficiente para extingui-lo.

Na categoria C3, "Providências perigosas ou que não solucionariam o problema", organizamos as ações que apresentaram algum grau de periculosidade ou que se apresentavam como uma tentativa falha, que não solucionariam o problema em questão. Nessa categoria temos a resposta de três estudantes: EC4, EC5 e EC8.

A resposta de EC4 traz a ideia de que não se pode acender a luz, o que está correto, pois, assim como justificado por ele, o ato de acender a luz pode gerar faíscas e provocar explosões. O estudante EC4 realizaria, contudo, a ação perigosa de retirar o botijão de dentro de casa.

O estudante EC5 também retiraria o botijão de dentro de casa, e ele apresentou como motivo dessa retirada, evitar uma explosão dentro da casa. 
A resposta do estudante EC8 está confusa, pois não é possível identificar qual seria o local a ser fechado por ele. Pode ser que ele tenha se referido ao ponto de vazamento. Mas parece que sua preocupação maior foi em relação ao odor insuportável e não a inflamabilidade.

Ao observar as respostas dos estudantes da escola do campo, percebemos que apenas um deles resolveria efetivamente o problema proposto, apontando as duas providências fundamentais nesse tipo situação e justificando suas ações. A maior parte desses alunos apresentou soluções parciais para o problema. Alguns ainda demonstraram uma forte preocupação com a possibilidade de haver explosões nessa situação, o que é realmente preocupante em caso de haver um vazamento real de gás, desde que haja a presença de uma fonte ígnea, que promova faíscas. No caso de um vazamento de pequena proporção, essa possibilidade pode ser descartada, desde que as medidas de segurança sejam tomadas. A maioria das providências por eles apontadas envolveu o ato de não acender ou apagar luzes ou de levar o botijão para fora de casa, considerando apenas o fator da inflamabilidade.

Independentemente da escola, a maioria dos estudantes pesquisados não resolveria esse problema de forma completa, pois não tomaria as providências fundamentais, além de alguns colocarem sua saúde em risco. Quando, contudo, analisamos as respostas de cada escola separadamente, percebemos que um maior número de estudantes da escola urbana - 5 estudantes ( $31 \%$ dos respondentes) - tomaria as providências fundamentais no sentido de solucionar o problema; em contrapartida, somente um estudante (11\% deles) da escola do campo o faria. Por outro lado, um número considerável de estudantes, de ambas as escolas, tomaria providências perigosas ou desnecessárias na tentativa de solucionar o problema, ou seja, 5 (31\%) dos estudantes da Escola Urbana e 3 (33\%) dos estudantes da escola do campo. Observamos também que um número expressivo de estudantes não justificou o motivo pelo qual tomaria determinada providência. Muito provavelmente, isto ocorreu porque eles desconhecem as relações de causa e efeito dessa situação, ou porque têm conhecimentos fragmentados sobre o assunto ou, ainda, porque apresentam dificuldade de explicar as suas opiniões de forma escrita.

\section{Análise do Problema 2: Poluição de um rio}

Problema 2: Aos domingos, você e alguns amigos costumam pescar em um rio nas proximidades de sua casa. Esse rio é famoso por sua água límpida e pela quantidade de peixes. Porém, certa vez, ao chegarem lá, vocês perceberam que alguém jogou no rio uma grande quantidade de embalagens de agrotóxicos. Considerando os riscos de contaminação do rio e sabendo que aquela água é a que abastece a sua casa e a população da região, o que você faria na tentativa de solucionar o problema?

No Problema 2 procuramos trazer uma situação hipotética que acontece em regiões agrícolas, onde é comum o uso de agrotóxicos e consequente despejo de agrotóxicos ou de embalagens desses produtos em rios próximos a plantações, causando a poluição 
de rios. Nesse tipo de situação, toda a população que depende direta e indiretamente daquele rio é afetada, sendo necessárias algumas medidas imediatas para corrigir ou minimizar o problema.

Como critérios de análise, consideramos como adequada todo tipo de estratégia relacionada à comunicação e/ou à responsabilização de órgãos competentes, pois eles têm a responsabilidade de corrigir/solucionar o problema, mesmo que de forma indireta, designando, por exemplo, agentes especializados para retirar as embalagens do rio. Porém, é importante ressaltar que, em casos de poluição de rios por embalagens de agrotóxico, há que se ponderar sobre o fato de que comunicar as autoridades sobre o problema nem sempre produz, necessariamente, a solução efetiva do problema, ou seja, nem sempre é obtida a despoluição/descontaminação apropriada do rio.

Levando em conta que, nesse problema, estamos avaliando a atitude de adolescentes, entendemos que a melhor forma de eles resolverem o problema seria informar as autoridades competentes. Consideramos como estratégias perigosas todo tipo de ação que envolva a retirada das embalagens pelos próprios estudantes, pois, mesmo que essa ação seja aquela que solucionaria efetivamente o problema em questão, essa medida envolveria riscos à vida deles, como a possibilidade de um afogamento ou de contaminação devido a coleta de embalagens sem a devida proteção. Outro problema vinculado à retirada das embalagens do rio é conseguir dar um destino correto para as embalagens.

Avaliamos como inadequado todo tipo de ação que não solucionaria o problema, como, por exemplo, o ato de procurar/encontrar as pessoas que causaram o problema, pois acreditamos que esta não é uma atitude que deva ser tomada por adolescentes. $\mathrm{Na}$ realidade, o fato de encontrar os causadores do problema não produziria uma solução para o mesmo, apenas implicaria uma atitude de responsabilizar aquele que causou o problema, providência que, efetivamente, deve ser tomada pelas autoridades competentes.

Na Figura 3, apresentamos as respostas dos estudantes da Escola Urbana e suas respectivas categorias, que a seguir são registradas e discutidas.

\begin{tabular}{|l|l|}
\hline C1 & Comunicação/Responsabilização dos órgãos competentes \\
\hline EU1: & $\begin{array}{l}\text { "acionaria imediatamente a empresa que possa tomar alguma providência, deixando-a ciente para que } \\
\text { possa resolver o problema" }\end{array}$ \\
\hline EU2: & $\begin{array}{l}\text { "Buscaria a prefeitura para tentar retirar ao máximo de poluentes do rio, ou tentar pegar água com } \\
\text { caminhões pegar até solucionarem o problema mantendo a rigidez na hora de filtrar a água em } \\
\text { [incompreensível] de tratamento" }\end{array}$ \\
\hline EU3: & "ia na prefeitura de minha cidade e iria reclamar para resolver tal caso e procurar as indústrias" \\
\hline EU4: & "chamaria a polícia ambiental e algum órgão especializado para descontaminação do rio" \\
\hline EU5: & "eu chamaria a prefeitura da cidade para eles solucionarem, estão ali pra isso" \\
\hline EU9: & $\begin{array}{l}\text { "contatar os órgãos municipais para que o rio tenha esses resíduos retirados e para que a empresa que } \\
\text { descartou as embalagens seja punida" }\end{array}$ \\
\hline EU8: & "Comunicaria as autoridades" \\
\hline
\end{tabular}

Figura 3. Respostas dos estudantes da Escola Urbana ao Problema 2 (continua) 


\begin{tabular}{|l|l|}
\hline C1 & Comunicação/Responsabilização dos órgãos competentes \\
\hline EU11: & "Ligaria para um órgão responsável” \\
\hline EU13: & $\begin{array}{l}\text { "chamaria os pesquisadores para olhar o nível de contaminação e aplicar a multa nos agricultores e } \\
\text { construir uma barragem com um filtro especial para isso e limpar em volta do lugar” }\end{array}$ \\
\hline C2 & Responsabilização daqueles que realizaram a ação \\
\hline EU6: & “primeiramente tentar localizar quem estava jogando lixo e denunciaria" \\
\hline EU7: & "tentaria achar o culpado e fazer com que ele ache uma solução" \\
\hline C3 & Realização da limpeza do rio por conta própria \\
\hline EU10: & "tentaria fazer a retirada dessas embalagens no máximo para tentar não deixar poluir o rio" \\
\hline EU12: & "iria limpar o rio" \\
\hline EU14: & $\begin{array}{l}\text { "conversaria com o governo do qual cuida do rio, com o IAP da situação do rio para eles fazerem } \\
\text { alguma coisa e juntaria as pessoas que utilizam daquele rio para começarmos por nós a limpar o rio" }\end{array}$ \\
\hline C4 & Informaria pais ou outras pessoas sobre o problema \\
\hline EU15: & "conversaria com meus pais para que me ajudem a encontrar solução” \\
\hline EU16: & "alertaria a vizinhança” \\
\hline
\end{tabular}

Figura 3. Respostas dos estudantes da Escola Urbana ao Problema 2 (continuação)

Fonte: as autoras

A partir da análise das respostas dos estudantes foi possível organizá-las em quatro categorias. Na categoria C1, "Comunicação/responsabilização dos órgãos competentes", temos as respostas dos estudantes que procurariam comunicar algum órgão competente sobre o problema, sendo ele público ou privado. Nessa categoria, temos as respostas de 9 estudantes - EU1, EU2, EU3, EU4, EU5, EU9, EU8, EU11e EU13. Isso significa que a grande maioria dos estudantes, em um caso como esse, tomaria a providência adequada na tentativa de solucionar o problema, comunicando alguma instituição responsável, como a prefeitura, por exemplo, para que ela tomasse as providências necessárias para resolver o problema.

De acordo com a legislação, em casos de poluição/contaminação ambiental de rios, a ação de correção do problema é responsabilidade subjetiva do Estado, ou seja, o Estado é o órgão que deve tomar as providências cabíveis de responsabilização civil e criminal daquele que causou danos ao meio ambiente e, no caso de um rio pertencente a um município, a prefeitura do município representaria o Estado e tomaria as providências cabíveis. Essas informações podem ser encontradas na Lei Federal no 6.938/1981, que instituiu a Política Nacional do Meio Ambiente. Nesta lei, cabe destacar o parágrafo $1^{\circ}$ do artigo 14, que diz:

Sem obstar a aplicação das penalidades previstas neste artigo, é o poluidor obrigado, independentemente da existência de culpa, a indenizar ou reparar os danos causados ao meio ambiente e a terceiros, afetados por sua atividade. O Ministério Público da União e dos Estados terá legitimidade para propor ação de responsabilidade civil e criminal, por danos causados ao meio ambiente (Lei Federal no 6.938/1981).

Destacamos as respostas dos estudantes EU1 e EU9, os quais responsabilizam 
uma empresa como sendo o órgão que deve solucionar o problema, mas as suas afirmações não estão claras. O estudante EU9 deduziu que foi uma empresa a causadora do problema, mas isso não pode ser afirmado pelo estudante, pois não há informações sobre isso no enunciado.

EU4 mencionou que "chamaria a polícia ambiental e algum órgão especializado para descontaminação do rio", sendo essa também uma atitude coerente, pois a polícia ambiental e outros órgãos especializados do Estado têm autonomia para tomar medidas cabíveis na busca da solução para o problema e/ou para a responsabilização dos culpados.

A resposta de EU13 se diferenciou das demais, pois o estudante mencionou que chamaria pesquisadores, que poderiam mensurar o nível de contaminação no rio. $\mathrm{O}$ estudante dirige a responsabilidade aos pesquisadores, dando a entender que eles possuem o conhecimento para propor soluções para o problema. Ele menciona que os pesquisadores poderiam construir uma barragem para conter as embalagens e essa é uma sugestão que parece viável, uma vez que isso poderia solucionar parte do problema, impedindo um desastre maior. Há, entretanto, uma incoerência na resposta quando atribui ações - de aplicar multas e de construir barragens - aos pesquisadores. Pesquisadores, em geral, propõem soluções, mas não executam esse tipo ação, pois isso é remetido aos órgãos competentes.

Na categoria C2, intitulada "Responsabilização daqueles que realizaram a ação", temos as respostas dos estudantes EU6 e EU7, que informaram que tentariam encontrar o culpado, responsabilizando-o pelo problema causado, como já nos referimos anteriormente. $\mathrm{Na}$ realidade, responsabilizar é dever do Estado e não pode ser uma atitude que adolescentes devam tomar.

Na categoria C3, "Realização da limpeza do rio por conta própria", os estudantes EU10, EU12 e EU14 tentariam limpar o rio por conta própria. Esta não é uma ação segura, pois os adolescentes e as pessoas em geral não têm preparo para realizá-las com segurança.

A resposta de EU14 merece destaque, pois o estudante mencionou que informaria os órgãos competentes sobre a situação do rio, tomando uma atitude coerente. Por outro lado, ele também sugeriu que faria a limpeza rio por conta própria e que ainda chamaria outras pessoas para ajudá-lo, consideramos essa uma ação que coloca em risco a sua integridade física e a de outras pessoas.

$\mathrm{Na}$ categoria C4, "Informaria pais ou outras pessoas sobre o problema", temos as respostas dos estudantes EU15 e EU16, que informaram que levariam o caso ao conhecimento de um adulto ou de seus responsáveis. Consideramos que essas também são atitudes possíveis, que dirigem a responsabilidade aos pais ou responsáveis, para que eles, indiretamente, resolvam o problema. Pensamos que essa é uma ação adequada, especialmente quando não se sabe que decisão tomar, embora a situação exija a tomada de decisão de outras pessoas.

Sob nosso ponto de vista, os estudantes resolvem o problema responsabilizando "o outro", sejam entidades ou pessoas. Para eles, o problema está aquém de suas 
responsabilidades ou possibilidades. Por outro lado, parece que os estudantes que tentam por conta própria resolver o problema, se consideram responsáveis por danos causados ao meio ambiente e adotam atitudes que poderiam ser tomadas por qualquer cidadão em defesa do meio ambiente. No entanto essas ações ignoram, impensavelmente, os riscos dessas decisões.

Dessa forma, podemos considerar que a maioria dos estudantes - 9 (56\%) deles - tomaria as providências corretas, buscando informar órgãos públicos, os quais são os responsáveis por procurar os culpados e obrigá-los por força de lei resolver/minimizar o problema. Neste caso a tomada decisão por parte dos estudantes está adequada.

$\mathrm{Na}$ Figura 4 temos as respostas dos estudantes da escola do campo, as quais foram organizadas em duas categorias C1 e C2.

\begin{tabular}{|c|l|}
\hline C1 & Realização da limpeza do rio por conta própria \\
\hline EC1: & $\begin{array}{l}\text { "Tentaria retirar as embalagens e colocaria placas próximas ao rio, com leis que dizem a respeito à } \\
\text { degradação ao meio ambiente e poluição de rios e nascentes, e se descobrir quem foi levaria o caso as } \\
\text { autoridades" }\end{array}$ \\
\hline EC2: & $\begin{array}{l}\text { "Eu tentaria tirar as embalagens da água ou chamaria agentes do meio ambiente para solucionar esse } \\
\text { problema" }\end{array}$ \\
\hline EC5: & "Faria a retirada do máximo de lixo possível" \\
\hline EC6: & "tentar retirar as embalagens tóxicas" \\
\hline EC8: & "Limpar o rio para ter um lugar mais limpo e não contaminado" \\
\hline C2 & Informaria os órgãos competentes \\
\hline EC3: & "Avisaria as autoridades responsáveis por cuidar da preservação do meio ambiente" \\
\hline EC4: & "Chamaria o responsável pelo local para tomar a providencia necessária" \\
\hline EC7: & "Faria contato com agentes ambientais imediatamente" \\
\hline EC9: & $\begin{array}{l}\text { "Falaria para os órgãos competentes que tratarão a água no caso (Sanepar) vendo o que poderia ser } \\
\text { feito" }\end{array}$ \\
\hline
\end{tabular}

Figura 4. Respostas dos estudantes da Escola do Campo ao Problema 2

Fonte: autoras

$\mathrm{Na}$ categoria $\mathrm{C} 1$, "Realização da limpeza do rio por conta própria", temos a resposta de cinco estudantes - EC1, EC2, EC5, EC6 e EC8 -, os quais tentariam resolver o problema de modo mais intempestivo, retirando as embalagens do rio. Essa atitude pode estar relacionada ao modo pelo qual o estudante entende o uso desses produtos, ou seja, de esses produtos fazerem parte do seu cotidiano. Se esses estudantes veem pessoas próximas manipularem agrotóxicos nas lavouras, por exemplo, então essa ação pode não significar um problema para eles. Consideramos que essa é uma atitude que poderia solucionar o problema, mas que carrega consigo vários perigos, como já foi discutido anteriormente.

$\mathrm{Na}$ categoria C2, "Informaria os órgãos competentes", temos a resposta de quatro estudantes, EC3, EC4, EC7 e EC9, que informariam os órgãos competentes ou buscariam informação com esses órgãos, considerando que essas sejam as atitudes coerentes a serem tomadas por esse público.

Destacamos a resposta de EC4, pois o estudante informou que chamaria o 
responsável pelo local, mas não explicou quem seria esse responsável, dando a ideia de que poderia ser uma pessoa em especial e não um órgão ou entidade pública.

A maior parte dos estudantes da Escola do Campo - 5 (56\% dos respondentes) - tomaria providências perigosas, que não são adequadas para serem tomadas por adolescentes ou por qualquer outra pessoa sem um preparo específico. Em contrapartida, um maior número de estudantes da Escola Urbana - 10 (63\% dos respondentes) tomaria as providências mais adequadas no que se refere a chamar a ajuda de órgãos competentes. Entre os estudantes que se propõem a solucionar o problema por conta própria não observamos, em suas respostas, a explicação sobre a forma como eles resolveriam o problema, ou seja, como fariam para retirar as embalagens do rio sem correr riscos, caso essa fosse uma atitude correta.

\section{Problema 3: Incidência de cáries dentárias}

Problema 3: Se você tivesse que tomar uma decisão em nível sanitário envolvendo o controle e a redução de cáries dentárias em uma população acometida pelo problema, qual/is providência/s você tomaria para reduzir a incidência de cáries dentárias nessa população? Explique.

Essa questão hipotética consiste em um problema de saúde pública, relativo ao controle e à redução de cáries dentárias em uma população, levando em conta que a erradicação definitiva do problema é muito difícil, pois envolve uma série de fatores (Lima, 2007). Nossa intenção foi analisar as estratégias utilizadas pelos estudantes para solucionar o problema da incidência de cáries. Consideramos que, para solucioná-lo, seria necessária uma combinação de medidas preventivas relacionadas ao controle das cáries, adicionadas de medidas corretivas envolvendo o tratamento adequado (Lima, 2007), isto porque que, quando uma população já possui cáries dentárias, somente medidas preventivas não resolvem o problema, pois medidas preventivas servem apenas para evitar cáries futuras e não para erradicá-las.

Dessa forma, consideraremos que todos os tipos de ações/medidas preventivas e corretivas empregadas de modo combinado são estratégias que solucionariam efetivamente o problema, envolvendo, por exemplo, fazer um tratamento com um dentista, campanhas de conscientização sobre o problema, divulgação de técnicas de higiene e limpeza bucal, além de outras ações como a distribuição de kits de higiene bucal. Diante disso, consideramos as medidas apenas corretivas ou apenas preventivas (empregadas de forma separada) como estratégias que não solucionariam o problema.

É importante lembrar que desde 1954 são tomadas providências para evitar e diminuir o aumento das cáries dentárias na população brasileira. Segundo dados do Ministério da Saúde, a fluoretação, ou seja, a adição de flúor em águas de abastecimento público promove a redução da prevalência da cárie e reduz a velocidade de progressão de novas lesões (Brasil, 2009). Ainda de acordo com esse órgão de saúde, essas medidas têm diminuído expressivamente a incidência de cáries na população.

Temos também que destacar que qualquer medida tomada no sentido de diminuir 
ou, mais especificamente, de acabar com as cáries dentárias, depende muito mais das pessoas do que das ações propostas por entidades públicas. Ou seja, nenhuma medida soluciona em definitivo o problema, apenas pode atenuá-la se as pessoas tiverem mais cuidado com a higiene bucal. Nesse sentido, o acesso à informação e a bens e serviços que contribuam para essa causa podem diminuir substancialmente o problema. Além disso, quanto mais ações de saúde pública forem realizadas no sentido de acabar com as cáries dentárias, menor será a incidência de cáries na população.

$\mathrm{Na}$ Figura 5, apresentamos as respostas dos estudantes da Escola Urbana.

\begin{tabular}{|c|c|}
\hline $\mathrm{C1}$ & Medidas preventivas e corretivas \\
\hline EU2: & "Uma melhor conscientização para higiene bucal, atendimento público com dentistas, etc." \\
\hline EU4: & "melhoraria a saúde pública e faria campanhas de conscientização" \\
\hline EU9: & $\begin{array}{l}\text { "adição de flúor em quantidade maior a água, realizar campanhas de saúde bucal e investir em } \\
\text { tratamento odontológico público" }\end{array}$ \\
\hline EU10: & $\begin{array}{l}\text { "projetos em locais como em escolas explicando a importância da boca, dentistas públicos para } \\
\text { cuidar da população" }\end{array}$ \\
\hline EU11: & "escovas de dentes iriam ser distribuídas nos postos de saúde e aumentaria o número de dentistas" \\
\hline $\mathrm{C2}$ & Medidas preventivas \\
\hline EU3: & $\begin{array}{l}\text { "faria uma grande divulgação para cuidar dos dentes para reduzir a cárie dentária, e distribuiria } \\
\text { panfletos para fazer o povo escovar" }\end{array}$ \\
\hline EU16: & "propaganda que induzissem a cuidar da saúde bucal" \\
\hline EU1: & "distribuição de escovas dentais para toda a população" \\
\hline EU7: & "distribuindo escovas e pastas de dente" \\
\hline EU13: & $\begin{array}{l}\text { "distribuição de kits de escovas de dente com pasta e fio dental, e fazendo umas palestras pela cidade } \\
\text { avisando e explicando sobre o problema" }\end{array}$ \\
\hline EU5: & "escovar os dentes 4 vezes ao dia, pois tira cáries" \\
\hline EU8: & "escovar mais os dentes." \\
\hline EU12: & "escovar os dentes passar fio dental e tals pois isso ajuda a não dar cáries" \\
\hline EU14: & $\begin{array}{l}\text { "primeiramente eliminar alimentos como doces que causam as cáries, entregaria a essas pessoas } \\
\text { produtos de limpeza como creme dental, escova, fio dental" }\end{array}$ \\
\hline EU15: & $\begin{array}{l}\text { "criaria alertas para que diminuíssem o consumo de doces mastigáveis e que escovassem mais os } \\
\text { dentes" }\end{array}$ \\
\hline C3 & Medidas corretivas \\
\hline EU6: & "convênios com odontos para o atendimento de famílias carentes" \\
\hline
\end{tabular}

Figura 5. Respostas dos estudantes da Escola Urbana ao Problema 3

Fonte: autoras

As repostas dos estudantes da Escola Urbana foram organizadas em três categorias. $\mathrm{Na}$ categoria C1, "Medidas corretivas e preventivas", estão as respostas dos estudantes que tomariam medidas de conscientização da população sobre o problema, como campanhas e divulgação sobre higiene bucal, e que tomariam medidas relacionadas à correção do problema com a melhoria da saúde pública odontológica, o que facilitaria o acesso ao tratamento dentário. Nessa categoria temos as respostas dos estudantes EU2, EU4, EU9, EU10 e EU11. 
Destacamos a resposta do estudante EU9, que foi o único a mencionar a questão do flúor. Ele mencionou que adicionaria flúor em maior quantidade na água com a finalidade de reduzir cáries dentárias e, além disso, realizaria campanhas de saúde bucal, investindo em tratamento odontológico público. Consideramos que essa é uma das respostas mais coerentes, pois ele mostrou que conhece um pouco sobre o assunto em pauta. Faltou a ele, contudo, explicar as suas ideias fundamentando no conhecimento científico, esclarecendo o motivo pelo qual o flúor é adicionado à água de abastecimento, assim como explicar que a quantidade de flúor adicionado à água precisa obedecer a uma legislação, pois a adição dessa substância em altas concentrações pode acarretar em uma doença chamada fluorose, que acomete crianças que ingerem flúor em excesso, comprometendo toda a formação e desenvolvimento dentário (Brasil, 2009).

Na categoria C2, "Medidas preventivas", temos a resposta de dez estudantes: EU3, EU16, EU1, EU7, EU13, EU5, EU8, EU12, EU14 e EU15. Eles mencionaram várias medidas para prevenir ou evitar o problema, entre elas divulgação e conscientização sobre o problema, distribuição de escovas dentais ou de kits de higienização bucal, a diminuição dos doces, incentivos para a escovação mais frequente, entre outras medidas.

Chamou-nos a atenção a resposta do estudante EU5, que diz "escovar os dentes 4 vezes ao dia, pois tira cáries". Essa ideia é incoerente, pois o ato de escovar os dentes previne a formação de cáries, mas não as retira. Depois de formada a cárie, somente um dentista pode corrigir o problema, retirando a cárie e restaurando o dente. Os estudantes EU8 e EU12 mencionaram que o fato de escovar os dentes e/ou de passar fio dental com maior frequência pode solucionar o problema das cáries, o que também consiste em uma ideia inconsistente, pois essas são importantes ações de prevenção que podem evitar a formação de cáries, mas que sozinhas, não solucionam o problema. Para "acabar" com as cáries são necessárias várias ações preventivas e corretivas combinadas, inclusive a diminuição do consumo de doces, como mencionado por EU14 e EU15.

Na categoria C3, "Medidas corretivas", temos a resposta do estudante EU6, que mencionou a criação de convênios com dentistas para o atendimento de famílias carentes poderia ser uma forma de solucionar o problema das cáries dentárias na população. Sabese que essa medida corretiva é importante, mas não soluciona o problema porque seria necessário que toda a população tivesse acesso ao tratamento dentário e não somente uma parcela da população, sendo ela carente ou não. Além disso, medidas de correção sempre exigem custo maior do que as medidas de prevenção.

Diante desses dados, concluímos que apenas cinco estudantes, cujas respostas foram incluídas na categoria $\mathrm{C} 1$, tomariam as medidas corretivas e preventivas adequadas para solucionar o problema em questão, de modo a diminuir efetivamente o problema da cárie dentária da população. Os demais estudantes (a maioria) não solucionariam o problema ou o solucionariam parcialmente.

Apresentamos, a seguir, a análise das respostas dos estudantes da Escola do Campo ao Problema 3. 


\begin{tabular}{|l|l|}
\hline C1 & Medidas preventivas e corretivas \\
\hline EC2: & "Saneamento básico. Programas que ofereçam consultas médicas dentárias gratuitas" \\
\hline EC5: & "Saneamento básico, e acesso gratuito a rede de saúde" \\
\hline EC6: & "Disponibilizar dentistas e saneamento básico para que as crianças e adultos escovem os dentes" \\
\hline C2 & Medidas corretivas \\
\hline EC9: & "Faria uma mobilização de dentista interessado a ajudar voluntariamente fazendo um mutirão" \\
\hline EC4: & "Abriria acesso gratuito de atendimentos médicos" \\
\hline C3 & Medidas preventivas \\
\hline EC1: & $\begin{array}{l}\text { "Promovendo o uso da escova dental, o fio dental, promovendo a escovação correta, se reduz o } \\
\text { problema no motivo onde ele nasce, reduzindo assim, as cáries dentárias" }\end{array}$ \\
\hline EC7: & $\begin{array}{l}\text { "Ir em agencias de saúde e fornecer materiais para que toda população tivesse acesso à higiene básica } \\
\text { bucal, de qualquer idade e classe social" }\end{array}$ \\
\hline EC3: & $\begin{array}{l}\text { "Eu sairia distribuindo pasta e escova de dente e daria palestras de incentivo para as pessoas cuidarem } \\
\text { dos dentes" }\end{array}$ \\
\hline EC8: & "Fazer uma campanha com a população para ajudar com cáries dentárias" \\
\hline
\end{tabular}

Figura 6. Respostas dos estudantes da Escola do Campo a Questão 3)

Fonte: autoras

As repostas dos estudantes da Escola do Campo foram organizadas a partir das mesmas categorias da Escola Urbana. Na categoria C1, temos a resposta de três estudantes que propuseram medidas preventivas e corretivas relacionadas com a melhoria do saneamento básico e o tratamento odontológico gratuito da população. Interpretamos que as medidas de saneamento básico descritas pelos estudantes EC2, EC5 e EC6 se referem a medidas de melhoria no tratamento de água e às condições de higiene da população. Consideramos que essas respostas estão adequadas, pois combinam ações corretivas e preventivas para a solução do problema, apesar de as respostas carecerem de maior explicação.

$\mathrm{Na}$ categoria $\mathrm{C} 2$, temos a resposta de EC9 e EC4, que propõem medidas corretivas do tipo: mobilização de dentistas para tratar as pessoas com problema de cáries ou acesso ao atendimento médico-odontológico. Enfatizamos novamente que essas medidas não são suficientes para solucionar o problema.

As respostas de quatro estudantes foram incluídas na categoria C3: EC1, EC7, EC3 e EC8. Eles propuseram medidas preventivas do tipo: distribuição de escovas, incentivo à escovação e ao uso do fio dental, sensibilização da população por meio de palestras e de campanhas para reduzir as cáries dentárias, etc. Tais ações poderiam diminuir a incidência de cáries, mas, ainda assim, o problema não seria resolvido.

Ao analisar comparativamente os dados das duas escolas, percebemos que não foram dadas respostas diferenciadas e poucos estudantes solucionariam o problema. Apenas cinco, ou seja, 31\% dos estudantes da Escola Urbana, e três, ou seja, 33\% dos estudantes da Escola do Campo propuseram medidas de prevenção e de correção do problema que foram consideradas adequadas. Os demais (a maioria) não conseguiram propor medidas para solucionar o problema. 
Esses dados indicam que há falta de informação sobre o assunto e isso pode ser confirmado pelo fato de apenas um estudante ter mencionado, mesmo que de forma sucinta, que a fluoretação da água pode ajudar a solucionar esse problema de saúde pública. Embora esse estudante não tenha pensado em termos de níveis de concentração de flúor permitidos na água de abastecimento, ele faz referência ao conteúdo científico, pois identifica essa substância como uma possibilidade de solução para o problema.

\section{Considerações finais}

Em geral, observamos resultados semelhantes em ambas às escolas pesquisadas, o que pode estar relacionado ao modelo de ensino oferecido a esses estudantes. As respostas dos estudantes de ambas as escolas mostraram-se sucintas, e quando as comparamos, percebemos que na Escola do Campo essa característica se mostrou um pouco mais preocupante, pois as respostas dadas são ainda mais breves e superficiais. Este resultado pode estar relacionado a vários fatores, dentre eles, o grau de envolvimento dos estudantes com a pesquisa ou com o fato de a atividade não ter sido estimulante o suficiente para eles.

Os estudantes da Escola Urbana, em geral, apresentaram respostas diversificadas, que fogem de um padrão, necessitando de um maior número de categorias para alocálas. Isso, contudo, pode ter sido consequência do maior número de estudantes da Escola Urbana em relação à Escola do Campo, dado que, quanto mais estudantes, maior é a possibilidade de serem propostas respostas diferentes.

Em relação ao Problema 1, acerca do vazamento do gás de cozinha, notamos que a maioria dos estudantes apresentou dificuldade de solucioná-lo, pois não tomariam as providências fundamentais e eficazes para solucionar um vazamento de pequena proporção, por vezes colocando-se em risco. Esse problema necessita de uma avaliação cuidadosa por parte do solucionador, acerca dos aspectos envolvidos e das possibilidades de solução. Entretanto, ao que nos parece, ao tentar resolvê-lo, os estudantes tomam decisões um tanto intempestivas, sem muita reflexão e análise e, talvez como consequência, eles não conseguem justificar suas ações. Esse resultado pode indicar que os estudantes não estão habituados a solucionar esse tipo de problema, ou que desconhecem as possibilidades de solução e os motivos de tomar determinadas decisões, ou, ainda, podem ser decorrentes de falhas na construção do problema, por parte das pesquisadoras. Estas falhas podem estar relacionadas à exigência para que os estudantes não só expressassem suas atitudes frente a uma situação, mas que também justificassem essas ações. Outra hipótese se refere à falta de direcionamentos que subsidiassem a resolução do problema. Contudo, essas exigências do problema corroboram com as sugestões apresentadas na literatura em RP, que indicam a necessidade de o solucionador também justificar suas hipóteses ou ações frente a um problema, elaborando inclusive um argumento que sustente a tomada de decisão (Jimenez-Aleixandre, \& Agraso, 2006; Goi, 2014).

De modo geral, esses resultados nos fazem repensar o papel da educação 
escolar e da educação familiar na instrução de adolescentes nesse tipo de situação, independentemente do contexto em que estão inseridos. A responsabilidade da família é oferecer proteção e orientar os jovens quanto à conduta a ser tomada em caso de problemas cotidianos de ordem prática (Santos; Toniosso, 2014), instruindo quanto às medidas a serem tomadas em caso de um vazamento de gás de cozinha. Entretanto, fica a cargo da educação escolar explicar o fenômeno, apresentar e discutir os perigos envolvidos e os conhecimentos necessários para solucionar um problema dessa natureza.

$\mathrm{Na}$ análise do Problema 2, sobre a poluição de um rio por embalagens de agrotóxicos, obtivemos resultados divergentes, pois os estudantes da Escola Urbana demonstraram que solucionariam o problema responsabilizando os órgãos competentes. Enquanto, os estudantes da Escola do Campo apontam que tentariam resolver o problema por conta própria, colocando em risco a sua integridade física. Como no problema anterior, em geral faltam justificativas ou explicações claras sobre a forma como o problema seria resolvido pelos estudantes, especialmente quando eles citam que o resolveriam sozinhos.

Com relação ao Problema 3, envolvendo a incidência de cárie dentária em uma população. Percebemos que são poucos os estudantes, de ambas as escolas, que tomariam as providências eficazes nesse tipo de situação, apontando medidas preventivas e corretivas. Esses dados demonstram que há uma falta de informação sobre o assunto em ambos os grupos pesquisados, pois observamos, em suas respostas, certo desconhecimento acerca de que eles já fazem uso da água fluoretada de abastecimento público para prevenir e diminuir cáries dentárias. Somente um estudante da Escola Urbana falou sobre o processo de fluoretação da água nas estações de tratamento com a função de prevenir e de diminuir as cáries dentárias. Outro fato que nos chama a atenção é que alguns dos estudantes pesquisados acreditam que escovar os dentes "retira" a cárie dentária, o que não está correto do ponto de vista do conhecimento científico, como apontado anteriormente.

Independentemente do contexto em que a escola está inserida, esses resultados nos fazem refletir sobre a relevância de se discutir esse tipo de problema na Educação Básica e, mais especificamente no ensino de Ciências. Parece-nos que problemas com esse perfil precisam fazer parte dos currículos escolares, de modo que, como discutido por Santos e Mortimer (2001), propiciem aos estudantes momentos de reflexão, de discussão coletiva e de tomada de decisão sobre questões sociais que, de uma forma ou de outra, interferem no cotidiano das pessoas em diferentes contextos.

A partir da compreensão de problemas específicos é que os estudantes poderão buscar o entendimento de problemas sociais de maior amplitude, e poderão participar de debates ou de decisões comuns da sociedade. Mas isso só acontecerá se eles vivenciarem esse tipo de situação ao longo de sua formação. A nosso ver para que alcancemos os objetivos formativos que almejamos, é fundamental uma mudança nas práticas didáticopedagógicas desenvolvidas por professores nas aulas de Ciências, assim como uma reorganização do currículo escolar, de modo a contemplar abordagens metodológicas 
diversificadas, como, por exemplo, a RP (Echeverría, \& Pozo 1998).

Com relação à Resolução de Problemas do cotidiano, podemos inferir que os estudantes de ambas as escolas privilegiaram o conhecimento de senso comum e utilizaram pouco o conhecimento científico escolar, mesmo considerando que a pesquisa foi realizada em um contexto escolar, o que gera a expectativa de que o discurso acerca do conhecimento científico escolar prevalecesse. A prevalência do conhecimento de senso comum pode estar relacionada tanto à natureza dos problemas, quanto ao fato de eles discutirem pouco sobre o assunto na escola. Reforçamos que esses resultados podem ser consequência das próprias práticas escolares de RP na Educação Básica, que tendem a estar mais centradas em tarefas rotineiras ou delimitadas e com escasso significado científico para os estudantes, que passam a ter dificuldade de relacionar suas experiências cotidianas com os conhecimentos científicos escolares (Pozo, \& Crespo, 2009).

Também não foram encontrados indícios de que os estudantes conheçam ou utilizem algum modelo ou estratégia de resolução de problemas (Gil Pérez et al., 1992; Lopes, 1994; Echeverría \& Pozo, 1998). Isto era esperado, pois esse tipo de abordagem não é utilizado com frequência pela professora da disciplina e, provavelmente, também não o é por outros professores das turmas pesquisadas.

Se desejamos preparar mais adequadamente estudantes para participar da vida em sociedade, é preciso desenvolver práticas que favoreçam também a capacidade de tomada de decisão e a aprendizagem de atitudes responsáveis no ensino de Ciências (Santos, \& Mortimer, 2001). A habilidade de solucionar problemas precisa ser desenvolvida/ exercitada no decorrer de toda a caminhada escolar dos estudantes (Aguiar, 2011). Mas, para isso é necessário investimentos em formação inicial e continuada de professores para que eles tenham a oportunidade de conhecer diferentes alternativas de abordagem conceitual e metodológica e possam empregar adequadamente as possibilidades da abordagem de Resolução de Problemas, especialmente na Educação Básica (Goi, 2014).

Conhecer a forma como os estudantes resolvem problemas do cotidiano nos permite refletir sobre a forma como eles compreendem os problemas do cotidiano e isso nos permite também fazer aproximações quanto à forma como os problemas estão sendo tratados em alguns contextos escolares brasileiros.

Ainda com relação à pesquisa, não podemos deixar de mencionar que não é tarefa fácil construir e analisar de problemas, especialmente problemas abertos, os quais apresentam natureza subjetiva e, por vezes, não possuem respostas ou soluções prontas. Mesmo assim, sem dúvida, o potencial desses problemas está em possibilitar que ocorram reflexões e discussões relevantes nas salas de aula nas disciplinas de Ciências.

$\mathrm{O}$ fato de construirmos problemas relacionados ao cotidiano não favoreceu a sua resolução justificada, possivelmente devido à natureza do problema e a falta de relevância dos mesmos para os estudantes. Outro fator pode estar relacionado às dificuldades de leitura e de escrita, ou ainda às dificuldades de interpretação e compreensão dos enunciados, como foi apontado na pesquisa realizada por Amaral (2010), por exemplo. 
Como discutido anteriormente, são muitos os fatores que interferem na composição desses resultados e que não podem ser desconsiderados. Entretanto, diante de uma realidade educacional que muitas vezes não privilegia situações problemáticas e instigantes, entendemos ser necessário valorizar toda e qualquer tentativa dos estudantes de solucionar problemas, de acordo com o conhecimento que possuem e que lhes é disponibilizado.

Essa pesquisa ofereceu como contribuição à área uma possibilidade de análise de problemas abertos, que podem vir a ser empregados no ensino de Ciências da Educação Básica. Além disso, foram disponibilizados resultados não muito animadores, que merecem atenção e que reforçam a importância de inserir atividades de RP nos currículos da Educação Básica das escolas brasileiras.

Por fim, ressaltamos a necessidade de aprofundar as pesquisas nesse campo, pois o nosso universo de análise, uma escola urbana e uma escola do campo, é um tanto limitado para a realização de maiores extrapolações. Portanto, é necessário que outras pesquisas sejam realizadas, em contextos escolares diversificados, com vistas à proposição de diferentes atividades de Resolução de Problemas em sala de aula, que possam favorecer a reflexão crítica acerca de problemas da vida real, desenvolver a tomada de decisão e proporcionar o emprego dos conhecimentos científicos pelos estudantes. Assim, é possível apontar caminhos para a melhoria das práticas pedagógicas com a RP no ensino de Ciências.

\section{Agradecimentos}

À Coordenação de Aperfeiçoamento de Pessoal de Nível Superior (CAPES), pela concessão de bolsa de Mestrado no Programa de Pós-Graduação em Educação da Universidade Estadual do Oeste do Paraná (PPGE/Unioeste).

\section{Referências}

Aguiar, E. V. B. (2011). Aprimoramento das habilidades cognitivas de resolução de problemas com o apoio de um agente conversacional. (Tese de Doutorado em Informática na Educação). Programa de Pós-Graduação da Universidade Federal do Rio Grande do Sul, Porto Alegre.

Amaral, E. T. (2010). O professor de ensino médio e o seu olhar sobre a leitura e a escrita em sua disciplina. (Dissertação de mestrado em Educação). Programa de Pós-Graduação da Universidade Metodista de Piracicaba, São Paulo.

Corpo de Bombeiros de São Paulo (2011). Cartilha de orientações básicas. Noções de prevenção contra incêndio: Dicas de Segurança. São Paulo, SP: Versão 05.

Costa, S. S. C., \& Moreira, M. A. (2006). Atualização da pesquisa em resolução de problemas: informações relevantes para o ensino de Física. In. Atas I Encontro Estadual de Ensino de Física (p.153). Porto Alegre, Instituto de Física-UFRGS. 
Echeverría, M. P. P., \& Pozo, J. I. (1998). Aprender a resolver problemas e resolver problemas para aprender. In J. I. Pozo, (Org.). A solução de problemas: aprender a resolver, resolver para aprender. (p. 13-42). Porto Alegre: ArtMed.

Fontana, E. A. (2015). A resolução de problemas do cotidiano e de aplicação e o ensino de estatística nos anos finais do ensino fundamental. In Anais do VII Encontro de Pesquisa em Educação e III Congresso Internacional Trabalho Docente e Processos Educativos. (p.10). Uberaba, MG/Brasil: UNIUBE.

Francisco Jr., W. E., Ferreira, L. H., \& Hartwig, D. R. (2008). A dinâmica de resolução de problemas: analisando episódios em sala de aula. Ciências e Cognição. 13(3), 82-99.

Freire, M. S., Silva Júnior, G. A. da, \& Silva, M. G. L. (2011). Panorama sobre o tema resolução de problemas e suas aplicações no ensino de química. Acta Scientiae. 13(1), $106-120$.

Gil Pérez, D., Torregrosa, J. M., Ramírez, L., Dumas-Carrée, A., Gofard, M., \& Carvalho, A. M. P. (1992). Questionando a didática de resolução de problemas: elaboração de um modelo alternativo. Caderno Catarinense de Ensino de Física. Florianópolis: UFSC, 9(1), $7-19$.

Goi, M. E. J. (2014). Formação de professores para o desenvolvimento da metodologia de Resolução de Problemas na Educação Básica. (Tese de doutorado em Educação). Universidade Federal do Rio Grande do Sul, Porto Alegre, Rio Grande do Sul.

Huanca, R. R. H. (2006). A resolução de problemas no processo ensino aprendizagemavaliação de matemática na e além da sala de aula. (Dissertação de mestrado em Educação Matemática). Universidade Estadual Paulista, Rio Claro, São Paulo.

Jimenez-Alexandre, M. P., \& Agraso, M. F. (2006). A argumentação sobre questões sociocientíficas: processos de construção e justificação do conhecimento em sala de aula. Educação em Revista, 43(1), 13-35.

Jessup, M. N., Oviedo, P. E., \& Castellanos, R. P. (2000). La resolución de problemas y la educación en Ciencias Naturales. Pedagogia y Saberes, 13(1), 1-8.

Lei n. 6.938, de 31 de agosto de (1981). Dispõe sobre a Política Nacional do Meio Ambiente. Diário Oficial da União. Brasília, DF: Presidência da República Casa Civil.

Leite, L., \& Esteves, E. (2005). Ensino orientado para a aprendizagem baseada na resolução de problemas na Licenciatura em Ensino de Física e Química. In Actas VIII Congresso GalaicoPortuguês PsicoPedagogia, (p. 1752-1768). Braga, Portugal: Centro de Investigação em Educação do Instituto de Educação e Psicologia da Universidade do Minho.

Lima, J. E. O. (2007). Cárie dentária: um novo conceito. $R$ Dental Press Ortodon Ortop Facial. Maringá, 12(6), 119-130.

Lopes, J. B. (1994). Resolução de problemas em Física e Química: modelo para estratégias de ensino-aprendizagem. Lisboa: Texto Editora. 
Marques, G. Q., \& Cunha, M. B. (2015). Questões contextualizadas: uma análise de desempenho de estudantes de escola pública e particular. In Anais IV Congresso Paranaense de Educação em Química (p. 126) Curitiba, PR.

Ministério da Saúde (2009). Guia de recomendações para o uso de fluoretos no Brasil. Série A: Normas e Manuais Técnicos. Brasília, DF: Ministério da Saúde.

Nieto, P. V. (2002). La resolución de problemas em la enseñanza de lãs ciencias: aspectos didácticos y cognitivos. (Tesis de doctorado Ciencias de la Educacion). Universidad Complutense de Madrid, Espanha.

Ocampo, D. M. A. (2015). Resolução de problemas como uma interface interdisciplinar entre a Matemática e o ensino de Ciências. (Dissertação de mestrado em Educação em Ciências). Universidade Federal de Santa Maria, Rio Grande do Sul.

Oñorbe, A. (2003). Resolución de problemas. In Jimenez-Aleixandre, M. P., Caamaño, A. e Oñorbe, A. (Orgs.). Enseñar ciencias. (pp. 73-93). 3. ed., Barcelona, Espanha: Editorial Grao.

Palacios, F. J. P. (1998). La resolución de problemas en la didáctica de las ciencias experimentales. Revista Educación y Pedagogía. X(21), 119-143.

Pozo, J. I., \& Crespo, Á. G. (1998). A solução de problemas nas ciências da natureza. In Pozo, J. I. A solução de problemas: aprender a resolver, resolver para aprender. (pp. 67-102). Porto Alegre: Artmed.

Pozo, J. I., \& Crespo, M. A. G. (2009). A aprendizagem e o ensino de ciências: do conhecimento cotidiano ao conhecimento científico. 5. ed., Porto Alegre: Artmed.

Sá, L. P., (2010). Estudo de casos na promoção da argumentação sobre questões sócio-científicas no ensino superior de química. (Tese de doutorado em Ciências). Universidade Federal de São Carlos. São Paulo.

Santos, W. L. P., \& Mortimer, E. F. (2001). Tomada de decisão para ação social responsável no ensino de ciências. Ciência \& Educação, 7(1), 95-111.

Santos, L. R., \& Toniosso, J. P. (2014). A importância da relação escola-família. Cadernos de Educação: Ensino e Sociedade, 1(1), 122-134.

Sigarreta, J. M., Rodríguez, J. M., \& Ruesga, P. (2006). La resolución de problemas: una visión histórico-didáctica. Boletín de la Asociación Matemática Venezolana, XIII(1), 53-66.

Sindigás. (2008). Sindicato Nacional das Empresas Distribuidoras de Gás Liquefeito de Petróleo. Gás LP no Brasil. Segurança: Gás LP é seguro. v. 4. $1^{\text {a }}$ edição. Rio de Janeiro. 


\section{Glessyan de Quadros Marques}

${ }^{\odot}$ https://orcid.org/0000-0002-3123-6441 Universidade Estadual do Oeste do Paraná Programa de Pós-Graduação em Educação em Ciências e Educação Matemática Cascavel, Brasil glessyan@hotmail.com.

\section{Marcia Borin da Cunha}

${ }^{0}$ https://orcid.org/0000-0002-3953-5198 Universidade Estadual do Oeste do Paraná Centro de Engenharias e Ciências Exatas Toledo, Brasil borin.unioeste@gmail.com

Submetido em 18 de Abril de 2018 Aceito em 18 de Agosto de 2018 Publicado em 30 de Agosto de 2018 